\title{
Sustainable urban requalification in Algiers as a way to recover deteriorated areas
}

\author{
M. Chabou-Othmani \\ EPAU, Polytechnic School of Architecture and Urbanism, Algeria
}

\begin{abstract}
The main objective of the National Diagram of Territorial Planning in Algeria is to create attractive and competitive conditions. This reveals a political will to create a balanced territory with the aim of rational and sustainable use of land in strategic sectors development. At a territorial level this has been expressed through large scale projects such as important infrastructures, housing programs, etc. At a metropolitan level urban planning tools (PDAU) were revised and a "Strategic Plan" was based on attractive projects such as the improvement of Algiers Bay, etc. At a local level, a few facilities were built and public leisure places were reorganized. However, these actions were decided in order to enhance the image of the capital, scarifying a requalification, which was meant to increase quality of life in urban places. Some particular neighborhoods are marginalized, under integrated and in failure. Though these areas present great opportunities for land use and interesting socio-economic conditions. Nowadays, urban requalification is also understood to be a strategy of institutional re-appropriation. This means to re-conquer lands, to create new land values, to rebuild centralities, to promote citizen participation, to integrate renewable energies, to protect heritage, etc.

Through a canvas in two neighborhoods in Algiers: Beb-El-Oued and Oued Ouchaieh, our contribution has been to outline the possibilities from the perspective of reoriented planning on an existing city.

Keywords: urban requalification, strategic planning, deteriorated areas, institutional recovery, improvement of quality of life, gentrification, Algiers.
\end{abstract}

\section{Introduction}

The city of Algiers has developed, until the end of the 1980s, gradually from the west to the east according to the different plans of urbanism in force. This growth accelerated in the 1990s, following the law on liberalization of land and the end of 
state property; a growth which has been qualified as uncontrolled and which has generated an important urban sprawl and the proliferation of illegal and informal housing.

The plans in force, especially the PDAU (Master Plan of Urban Planning) will be completely outdated and obsolete. A review was initiated in 2007, and Algiers has undertaken the implementation of its new Master Plan, which will be carried out and completed in 2014 by the engineering office "Park Expo" on behalf of la Wilaya of Algiers (province of Algiers), but not yet approved.

The new Master Plan, which proposes to break with traditional approaches, offers a global and integrated vision. This view seems to focus on the environmental aspects with the proposal of several Agri-parks on the periphery of the city to de-densify and slow down urban sprawl on the fertile lands of Mitidja.

Obviously, other orientations appear to have been set up with all sectors, particularly in terms of eradication of precarious and informal housing and consolidation of public spaces by creating the public space charter.

Parallel to the Master Plan, a Strategic Plan was developed; a plan that proposes concrete projects in the city of Algiers, playing the role formerly assigned to the POS (the Land Use Plan).

This plan seems to reflect the ideal image of Algiers by its new designers. The Strategic Plan proposes an intervention in four phases, the first of which focuses on reclaiming the waterfront; a project called "Mediterranean's pearls".

Our goal is to understand, through analysis of recurrences and occurrences in the speech by the project designers, their vision and demonstrate at the same time, through the study of two neighborhoods in the city (Beb-El-Oued and Oued Ouchaieh), that:

1. Governance of these plans and projects within this context, although it promotes participation, seems far from participatory discourse.

2. The priority assigned by the Strategic Plan does not correspod to reality, particularly socially. This does not identify a strategy as defined by the urban management approach. Also, and although authorities say there is agreement between the Master Plan and Strategic Plan, a gap is visible between the orientations of the one and the priorities of the other.

3. The projects proposed by the Strategic Plan generate eviction, socio-spatial marginalization and may be a real gentrification in the future. This is already underway by the re-housing policy.

\section{Participation and a limited understanding of the Strategic Plan}

If the PDAU is put under the authority of the province of Algiers, the projects to be undertaken are the responsibility of the same authority. The acting officer of all these projects seems to be the same, whether you are at the metropolitan level or at the municipal level [1].

The question of decentralization projects to municipalities is not visible. The scale of $1 / 25000$ is not a performance scale; the effective implementation of 
certain projects on the scale of the Algiers neighborhoods, such as the main bus station in Kouba, or the leisure park of the "sablettes", leads us to wonder about the role of local technical structures in the negotiation of development projects or redevelopment of their municipalities.

The province, according to the interview made by the magazine Lives of Cities with the park-expo representative, is responsible for establishing the new PDAU and provides visibility, structuring, guidelines and projects at the municipal level across the 1/10000th.

Furthermore, the implementation of the Strategic Plan elicited no consensus, and even less consultation with civil society. This plan, almost held secret at the central level of the province, has been the subject of media coverage. It was first displayed to the public for information on the intervention sites in 2012, then and during several lectures at university level, an exhibition to the National Conference of Urbanism, and at "Algiers House" on the occasion of the fiftieth anniversary of the independence of Algeria [2].

Citizens and civil society have been informed of the Strategic Plan without any involvement or participation in any degree whatsoever.

Stakeholder involvement was limited to consultation and dialogue with the representatives of the different municipalities of Algiers. Fifty-seven municipalities of the capital have been consulted and discussions with representatives would have given good results [1].

But the elected belong to the sphere of the representative democracy, with political objectives. Participation in the direction of the involvement of civil society and the citizen does not seem to be a concern of the central authorities. The use of experts in the field of urban development also seems to be limited to some researchers whose teachers are politically engaged with certain political parties.

If the guidelines of PDAU claim to respect citizens' complaints, citizens are unaware of the decisions being taken by the district of Algiers.

Our investigation into the two sites of Beb-El-Oued and Oued Ouchaieh confirmed the lack of consultation of local authorities, even less civil society, whose expectations are limited to the purchase of a new social house. The responsibility of the municipality seems to be limited to census families re-housing or on the list of future beneficiaries.

Local authorities (municipalities) themselves seem to be in the expectant. It is the district of Algiers that orders the actions to be taken at the municipal level. Moreover, discourse analysis of a representative office to study the revision of the Master Plan (PDAU) is very ambiguous about it. In any case, it implies a deletion of the role of municipality, the local authority.

Yet, it is the municipality which is the only interface with citizens and civil society. The surveys we conducted in the context of our research demonstrate the commitment of residents to their neighborhoods and to their solidarity. In the case of Beb-El-Oued, residents do not want to leave their neighborhood, but need an improvement in their life framework. Keeping the inhabitants in their neighborhoods is a major asset in the process of participatory urban regeneration.

The expectations of the population are reflected in terms of decent housing, work (neighborhood Beb-El-Oued with an unemployment rate of $24 \%$ ) and 
availability and efficiency of transport. But the projects proposed for Beb-El-Oued are leisure and fun projects. This suggests a shift has occurred between the expectations of the inhabitants of the observed areas and the nature of projects included in the Strategic Plan.

It has been demonstrated that citizen participation is essential for the legitimization of public action - shared responsibilities and decentralized decision-making is key to urban project success.

\section{Gap between reality and priorities of the Strategic Plan}

Development of the new PDAU has been reflected at 1/25000 scale with a global and integrated approach which is different to traditional approaches. However, this new vision incorporates both the development orientations and 82 registered development projects, 18 of which would be given priority as the relocation of the existing port of Algiers (Figure 1).

The Strategic Plan proposes concrete projects $(1 / 1000,1 / 500$ th scale and execution). The contracting authority is the county, but the municipality implements the project, its role is also not clarified in the approach.

The Strategic Plan of Algiers was thought out for the long term - specifically, for 2030. It includes six thematic plans:

1. The white plan, which is aimed at restructuring the city, especially with the creation of new facilities and of a broad housing program

2. The green plan that tries to restore the ecological balance

3. The blue plan that is primarily concerned with rational use of drinking water and recycling waste water, so not to have discarding in the sea anymore

4. The mobility plan - regulation and promotion of public and collective transport

5. The conservation plan - to spur job creation and encourage initiative

6. The social cohesion plan based on a policy of proximity and equipment in existing neighborhoods [1].

Its implementation was planned in four phases:

Phase 1: 2012-2016: Embellishment of the city

Phase 2: 2017-2021: The landscape of the Bay of Algiers

Phase 3: 2022-2026: The requalification of the periphery

Phase 4: 2027-2031: Consolidation of the city

Through the Strategic Plan, the authorities aim to change the image of the capital. It aims to give Algiers the value and the position it deserves, both in the Mediterranean region and in Africa. This image traces a legitimate aspiration, but also a willingness to change and improve the quality of life in its urban areas.

However, the Strategic Plan that has no legal basis, seems detached from the PDAU and has not yet been approved by the legal authorities.

A lot of the time spent in developing the Strategic Plan seems to have been about the importance of the projects in the Master Plan. Although the authorities argue that the Strategic Plan meets the guidelines of PDAU, the current superposition of the two plans is not possible. 


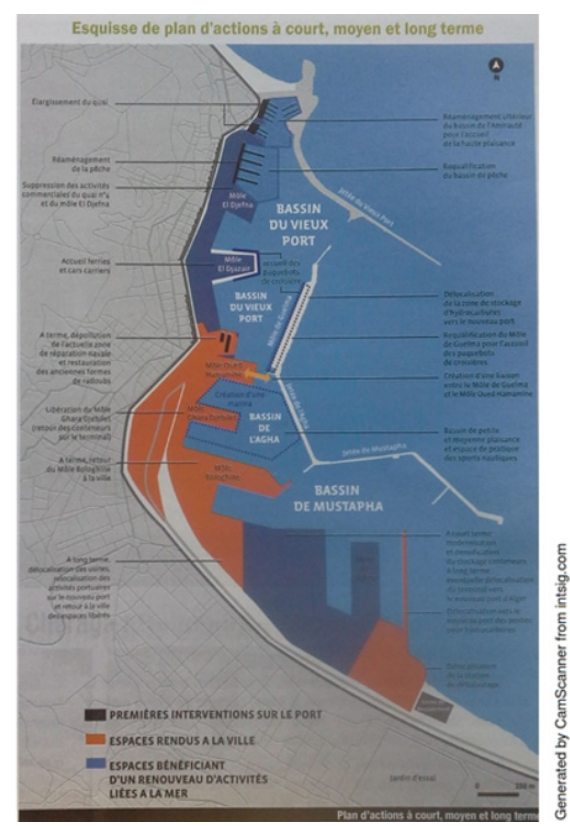

Figure 1: Sketch of the action plan of Algiers for short, medium and long terms $[1]$.

The eighteen priority projects proposed in the PDAU do not seem to find a consensus with the Strategic Plan. For example, the relocation of the port of Algiers is a priority for the PDAU, but is not in the Strategic Plan. It is important to remember that the port of Algiers is under the authority of the fisheries sector and not under the authority of the district or the municipality of Algiers-Center.

The Strategic Plan is not a plan of issues, objectives and actions; as is intended by the urban project approaches, but looks like a real POS (Land Use Plan). This translates, operationally, into the political vision of the ideal image to give to Algiers. This image reminds us of some international projects, including the Barcelona model or the Marseilles City Projects [3].

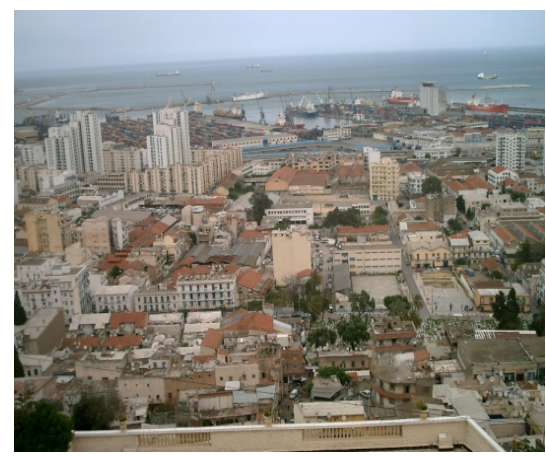

Figure 2: View of the port of Algiers. 
We focused primarily on the white plan, with the objective of urban restructuring, renewal of neighborhoods and rehabilitation of the medina of Algiers, declared World Heritage by UNESCO thirty years ago. Our approach is to check the priorities assigned by the two plans (PDAU and Strategic Plan).
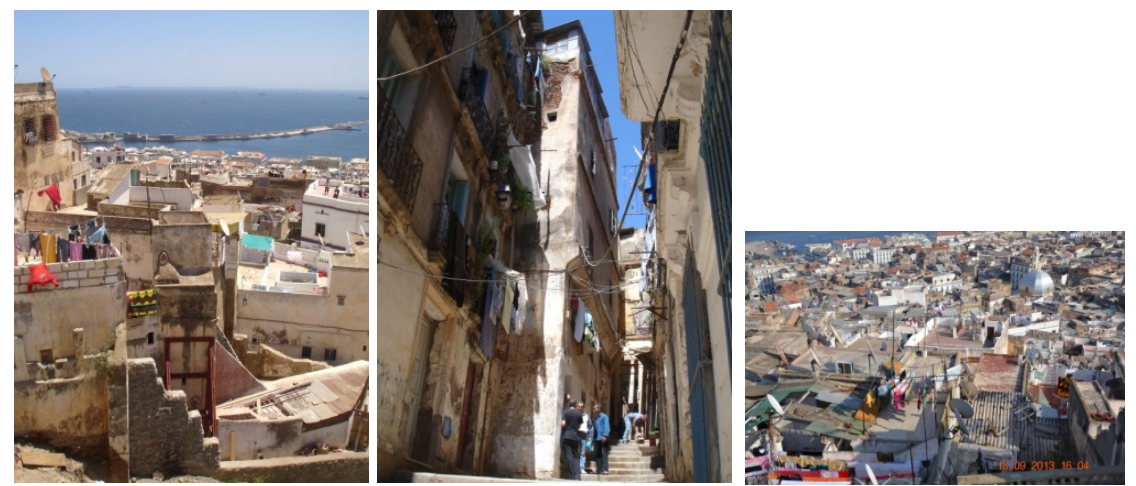

Figure 3: Different views on the old Casbah of Algiers.

This first plan, which focuses on the rehabilitation of the waterfront and the city-sea interface puts priority on showcasing the city to the sea. However it neglects the architectural and urban rehabilitation of older neighborhoods located more towards the interior of the city. The old buildings are deteriorated and no protection strategy is really established, or at least it does not seem clear by analyzing the Strategic Plan.

The only current plan is PPSMVSS (Protection Plan) of the Casbah of Algiers, whose vision focuses on the restoration of some residences and monuments without giving any indication on the future of the oldest part of the capital.

For the Strategic Plan, rehabilitation essentially means: the rehabilitation of underground networks, the development of public spaces, the reinforcement of buildings and the rehabilitation of facades. The operation of the "1st November" Avenue has focused on the apparent aspects of the avenue: elimination of satellite dishes, air conditioners, burying telephone cables and new flooring installation. These are certainly necessary, but completely superficial operations with regard to what should be an urban rehabilitation.
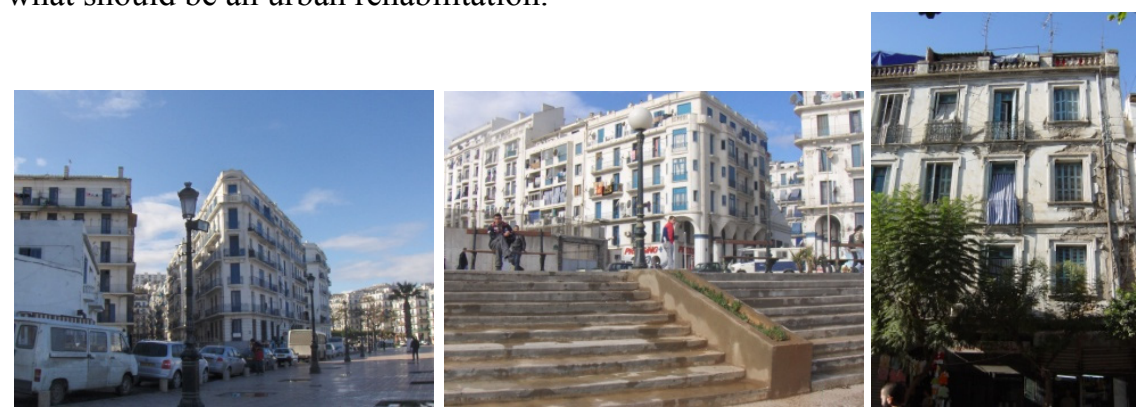

Figure 4: Different views of the old buildings of Beb-El-Oued. 
However, earthquakes, over-densification and the changes made by the inhabitants to their homes threaten the old buildings every day. The only policy adopted is that of the periphery relocation of hundreds of families in housing estates, designed entirely by the state.

Indeed, the PDAU advocates, wherever possible, to maintain the people in their neighborhoods, but the relocation policy does not seem to follow this directive. However, several examples in the world, especially in Europe, have shown that population relocation approaches threaten the social network. Today, social cohesion is advocated in different urban renewal policies, such as in France, through the law on social solidarity, but that does not seem to be the priority of the Strategic Plan for now.

Besides which, what is the meaning given by the authorities to the social cohesion plan? No device is set up to ensure social cohesion.

It is contradictory that the proposed projects are part of a global vision; however they do not integrate with the local reality. At least one wonders about the choice of projects and their involvement in the renewal process of the corresponding neighborhoods. Indeed, the projects included in the Strategic Plan are well defined, with their contracting and design offices, their surfaces, accommodation capacities and financial allocations. It is the equipment that varies according to different scales and that which has a national, metropolitan or local impact. Such as: "car park" projects, main bus stations, stadiums, leisure parks and promenades, hospitals, markets, public places, etc.

Analysis of Beb-El-Oued, located west of Algiers, which covers a coastal strip of $2 \mathrm{~km}$ and has a population of 64,732 inhabitants, shows that the projects under the Strategic Plan (promenades 1 and 2) for the neighborhood are not adequate to assert directly or indirectly on the improvement of some of the central areas of Algiers (Figure 5).

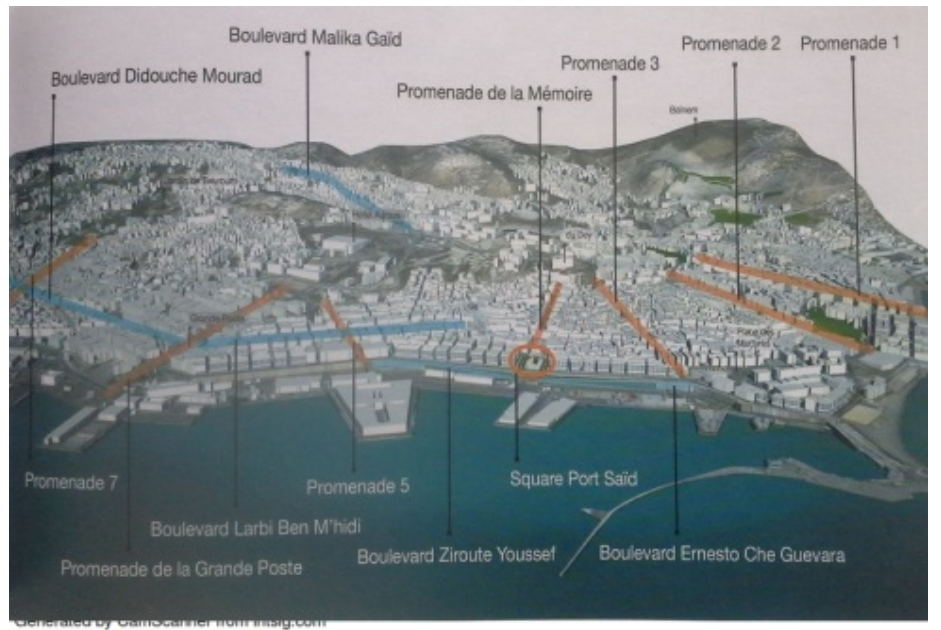

Figure 5: The different proposed promenades (promenades 1 and 2 in Beb-ElOued) [1]. 
This is an area that suffers with high residential density, with an occupancy rate of 5.7 per unit, but holds a dominant young population of $55 \%$ of the population, with a commercial dominating activity (but mainly informal trade), given the high unemployment rates.

The damaged buildings, whose typology is essentially colonial shape, makes life at Beb-el-Oued dangerous because of the risk of flood (2003 floods) and earthquakes. Following the last earthquake some Bologhine families were rehoused in the periphery.

Several buildings are already collapsing, empty lots left after demolition of damaged buildings, and excessive density in buildings that are still in good condition, etc. The diagnosis shows social isolation of this historic area, which contains very important assets, in favor of opening up a tourist attraction.

What impacts will the creation of two promenades and especially the planned leisure park have on the coast? What strategy can we detect through this choice?

It is easily observed that the Strategic Plan is not as strategic as it seems to be and that the analysis of technical data of the various proposed projects shows that they belong to different dominant sectors. The transport sector has been identified, sports sector, services and trade sector, housing sector (with OPGI H-Dey as a main contracting housing office) and the civil engineering sector. One could understand that these are sector projects compiled on the same plane.

The proposed projects do not come from a local diagnosis, to exploit the strengths of each district with clearly defined issues.

\section{Eviction, gentrification and socio-spatial marginalization}

The re-housing of inhabitants of deteriorated properties and slums respond to the logic of land recovery which leads to eviction, may be important for the realization of the central level projects already decided, but with social consequences.
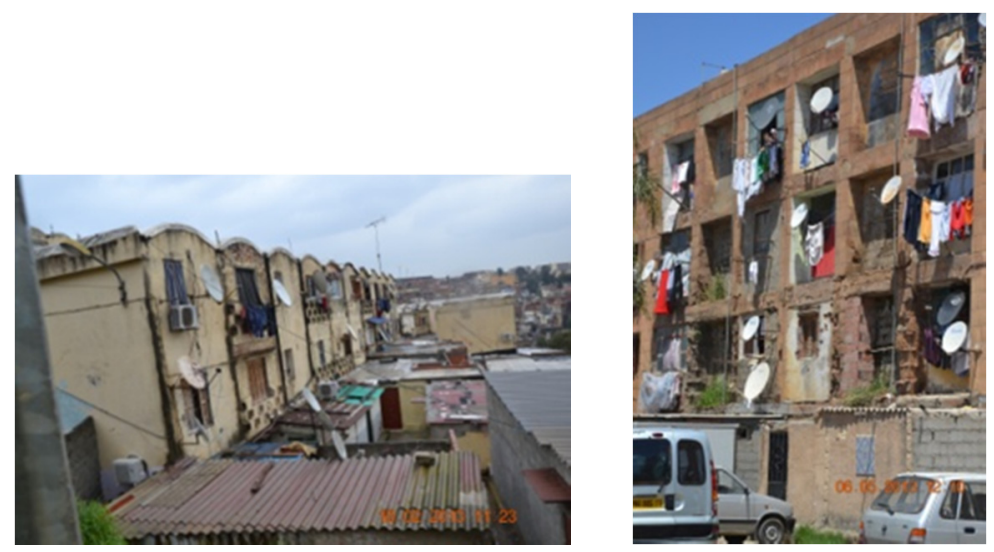

Figure 6: Precarious housing in Oued Ouchaieh (building on the right has been demolished in January 2015). 
The equation is as follows: to provide decent housing for the inhabitants of these neighborhoods on the periphery in order to recover the released land base.

An inhabitant who has lived all his life in bad conditions finds satisfaction in the purchase of a new house, however, it will be located far from his original area, even marginalized, and so he will have to build a new environment and adapt to a new life and a new neighborhood. But the marginalization of poverty is a theme of social protest, the right to urbanity in Europe in the 1980s, especially with "les grands ensembles", or suburban housing areas. What lessons need to be learnt to avoid the breakdown of social cohesion [4]?

The new housing areas offered are known as "green areas" and don't offer the quality specified in the political discourse either. The inhabitants are mostly forced to undertake modification or re-qualification of their living spaces. New settlements seem to offer an orderly framework, they are located in the periphery of major cities or villages and isolated compared to local facilities and transport infrastructure [5].

Architects and academics continue to criticize these new living spaces banality of architecture and styles, undersizing of space in relation to family size, lack of identity and reference to local conditions, failure to adapt to lifestyle and climate, etc.

Recovery of the land and existing empty buildings is not clarified. Are we moving towards an eviction, marginalization of poverty in Algiers and gentrification of the inner city, located mainly on the coasts?

The eviction of the inhabitant's process enables the recovery of land and insertion of projects that could create value. This approach, which the Algerian state automatically applies, is voluntarily or involuntarily a part of a gentrification via a new construction process [6].

Renovation (planned and demolitions already started) of the popular area of Oued Ouchaieh, whose urban component consists essentially of the resettlements (Bou-Maaza, the neighborhood of palm and several slums and auto-constructed housing), with a very poor and precarious architectural and urban typology, reflects the policy of eviction.
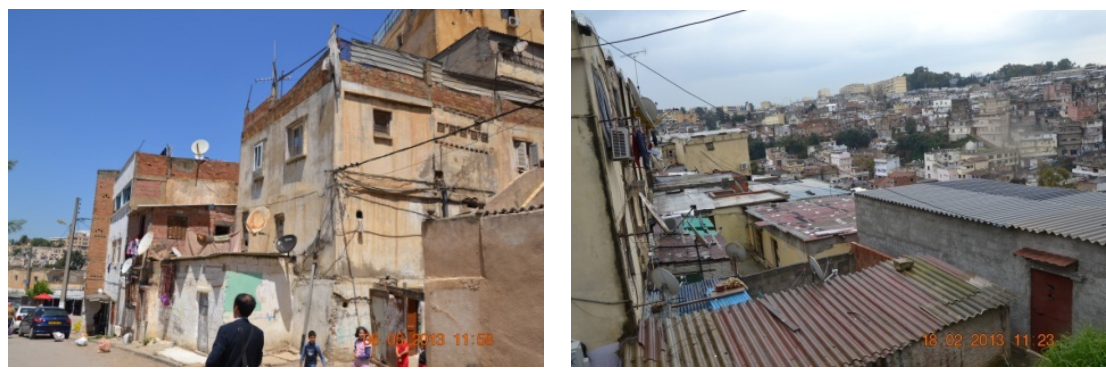

Figure 7: Auto-construction housing in Oued Ouchaieh.

Hundreds of families were re-housed as part of the eradication of an informal and precarious housing policy. This results in the demolition of released buildings. It follows a proposal for rewarding projects, and inducing a process of 
gentrification. The business district of Beb Ezzouar is an example that confirms this process.

The indicators of this process of gentrification result in, amongst other things, real estate strategies becoming increasingly frequent in the area, allowing the inhabitants of the neighborhoods around it to create added value, such as renting its house in favor of renting in an area located closer to the inner city, in a quest for city promotion.

In the case of the Oued Ouchaieh area, the projects under the Strategic Plan don't seem to support the argument of gentrification, although the land recovery in this area can contribute to a potential gentrification. The landscaped strengths of the area and its proximity to future projects under the Strategic Plan, such as the proposed development of the banks of El-Harrach River and the multimodal station, could make it a high value attractive neighborhood. Note that Le Corbusier envisioned for this site a gazebo project overlooking the sea, but this was never realized [7].

Ongoing demolitions are part of the project for the completion of the crossroads of Algiers. This is the construction of the viaduct Hussein Dey-Baraki, a length of $1 \mathrm{~km}$ and whose work had to be completed in 2014, but has been initiated recently.

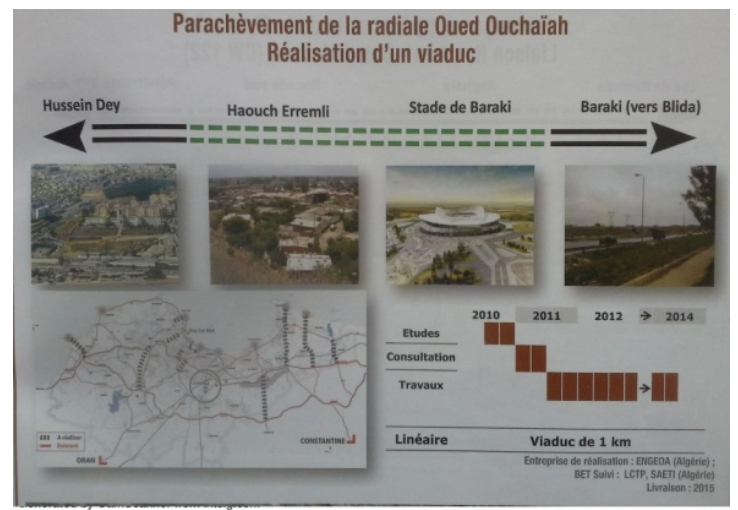

Figure 8: The plan of the viaduct of Oued Ouchaieh [1].

Again, there are actions undertaken by the Strategic Plan, but there is no strategy. The site of Oued Ouchaieh possesses landscape strengths that could have been a real opportunity for the development of residential neighborhoods with high property values, sustainable neighborhoods and eco-districts, to avoid spreading the periphery and back to the city with a more rational use of land.

\section{Conclusions}

The analysis of the Master Plan in relation to the potential of the two sites studied demonstrates the fragility of the Strategic Plan and its incompatibility with the Master Plan. 
The PDAU Algiers is still not approved by the authorities as a planning instrument with a legal basis, meaning that the realization of the Strategic Plan has no legal basis. And in case that the PDAU is approved, it would be null and void.

Also, the speed of the implementation of projects in the Strategic Plan, the exact definition of the size of the accommodation capacity, the location, the function, the contracting and design office, allows the supposition that the projects are sector-based projects, implemented independently but assembled in the same plane.

It seems to be difficult to talk about a Strategic Plan for two main reasons:

1. An urban strategy must result from a detailed analysis, strategic and shared by all actors within civil society with identified issues, prioritized scenarios and actions.

2. A strategy should be developed prior to the project. The project designs a response to the shared actions planned in the strategy.

A strategy and a project cannot be deployed in the same plane. This plan should be an opportunity to review the local instrument the POS (Local Land Use) which results legally from the PDAU (Master Plan). This review should include the establishment of a real urban renewal process involving both the central and sector-based authorities and local authorities.

This can only be achieved if there is a more effective and real reinforcement of local government with citizen involvement.

Obviously the affluence of Algeria in recent decades allowed the realization of scratch and development projects, regardless of issues related to the partnership and the use of local capacity. However, and since the last oil crisis, one wonders about the future of current and planned projects in the Strategic Plan of Algiers. Should we not better review this strategy by reinvesting more sustainable dynamics?

\section{References}

[1] Les Projets qui transforment Alger, in revue Vies de Villes, numéro hors série, Juillet 2012, Alger.

[2] Algerian Press: www.el-watan.com.

[3] Carrière J.-P., Villes et projets urbains en méditerranée, Presses universitaires François-Rabelais, France 2002.

[4] Chabou M., L'identité dans l'habitat Contemporain en Algérie, Personnal Communication, international Conférence on Housing in Algeria, learning to better acting, Laboratory "City Urbanisme \& sustainable development", EPAU, Algiers, November 2014.

[5] Dufaux F. \& Fourcault A., Le monde des grands ensembles, Editions Créaphis, Paris, 2004.

[6] Clerval A., Colomb C., Van Criekingen M., La gentrification des métropoles européennes, Données urbaines, PDF Document.

[7] L'attractivité des territoires: Regards croisés, Actes des séminaires, Février, Juillet 2007, PUCA. 